\title{
Phosphodiesterase 8B gene polymorphism in women with recurrent miscarriage: A retrospective case control study
}

\author{
Michaela Granfors ${ }^{1 *}$, Helena Karypidis ${ }^{1,2}$, Frida Hosseini ${ }^{2}$, Lottie Skjöldebrand-Sparre ${ }^{2}$, Anneli Stavreus-Evers ${ }^{1}$, \\ Katarina Bremme ${ }^{3}$, Britth-Marie Landgren ${ }^{4}$, Inger Sundström-Poromaa ${ }^{1}$, Anna-Karin Wikström ${ }^{1}$ and Helena Åkerud ${ }^{1}$
}

\begin{abstract}
Background: Recurrent miscarriage affects approximately $1 \%$ of all couples. There is a known relation between hypothyroidism and recurrent miscarriage. Phosphodiesterase 8B (PDE8B) is a regulator of cyclic adenosine monophosphate (CAMP) with important influence on human thyroid metabolism. Single nucleotide polymorphism (SNP) rs 4704397 in the PDE8B gene has been shown to be associated with variations in serum Thyroid Stimulating Hormone (TSH) and thyroxine (T4) levels. The aim of this study was to investigate whether there is an association between the SNP rs 4704397 in the PDE8B gene and recurrent miscarriage.
\end{abstract}

Methods: The study was designed as a retrospective case control study. 188 cases with recurrent miscarriage were included and compared with 391 controls who had delivered at least once and with no history of miscarriage or assisted reproduction.

Results: No difference between cases and controls concerning age was found. Bivariate associations between homozygous A/A (OR 1.57, 95\% Cl 0.98-2.52) as well as G/G carriers (OR 1.52, 95\% Cl 1.02-2.25) of SNP rs 4704397 in PDE8B and recurrent miscarriage were verified (test for trend across all 3 genotypes, $p=0.059$ ). After adjustment for known confounders such as age, $\mathrm{BMl}$ and smoking the association between homozygous $\mathrm{A} / \mathrm{A}$ (AOR 1.63, 95\% Cl $1.01-2.64, p=0.045)$ and $G / G(A O R 1.52,95 \% C l 1.02-2.27, p=0.039)$ carriers of SNP rs 4704397 in PDE8B and recurrent miscarriage remained.

Conclusions: Our findings suggest that there is an association between homozygous A/A as well as homozygous G/G carriers of SNP is 4704397 in PDE8B and recurrent miscarriage.

Keywords: Phosphodiesterase 8B, Recurrent miscarriage, Single nucleotide polymorphism, Thyroid

\section{Background}

Recurrent miscarriage affects approximately $1 \%$ of all couples trying to conceive and is defined as three or more consecutive pregnancy losses before 20 weeks of amenorrhoea [1,2]. Predisposing factors include maternal age, parental chromosomal aberrations, uterine abnormalities, antiphospholipid syndrome, immunological and thrombophilic disorders, and endocrine diseases such as hypothyroidism and diabetes mellitus [1]. Unlike sporadic spontaneous miscarriage, recurrent miscarriage

\footnotetext{
* Correspondence: michaela.granfors@kbh.uu.se

'Department of Women's and Children's Health, Uppsala University, Uppsala, Sweden

Full list of author information is available at the end of the article
}

more often occurs despite normal fetal cytogenetic findings, and in $50 \%$ of cases the underlying cause remains unexplained [1,3-5]. Hypothyroidism is a common disease, with an estimated incidence of $0.3 \%$ to $0.5 \%$ for overt and $3 \%$ for subclinical hypothyroidism in pregnant women $[1,6-8]$. There is a known relation between hypothyroidism and recurrent miscarriage [1].

The human phosphodiesterase type $8 \mathrm{~B}$ (PDE8B) gene is located at human chromosome 5q14.1 in intron 1 and encodes a high affinity cyclic adenosine monophosphate (cAMP) specific nucleotide phosphodiesterase [9-11]. The PDE8B gene is abundantly expressed in the thyroid but has also been detected in human placenta and ovaries $[9,10,12,13]$. Based on a recent genome-wide

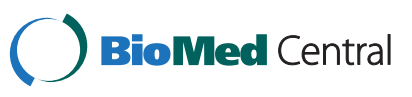


association study, six different single nucleotide polymorphisms (SNP) in the PDE8B gene were associated with increased serum concentrations of thyroid stimulating hormone (TSH) [14]. The strongest association with increased TSH levels (although in the normal range) was reported for one specific SNP in PDE8B, rs 4704397, which is found in the promoter region of the gene $[14,15]$. A recent meta-analysis confirmed the association between SNP rs 4704397 in PDE8B and elevated TSH levels, but also found an association with decreased levels of free T4, although free T3 levels were normal [16]. In addition, the association between SNP rs 4704397 in PDE8B and levels of TSH has been confirmed in pregnant women, although no association with free T3 or T4 levels was found [17].

In SNP rs 4704397 of PDE8B an adenine (A) nucleotide is replaced by a guanine $(G)$. The association between the polymorphism and high levels of TSH and low free T4 levels, indicating relative hypothyroidism, is found in homozygous carriers of A/A [16]. Based on previous results it has been proposed that the SNP rs 4704397 in PDE8B and in particular the presence of A alleles might induce increased phosphodiesterase activity in PDE8B, thereby reducing the ability of the thyroid gland to generate free T4 when stimulated by TSH [14]. Related to this, we hypothesized that homozygous carriers of A/A would be at increased risk of recurrent miscarriage. The aim of this study was to investigate whether there is an association between the SNP rs 4704397 in the PDE8B gene and recurrent miscarriage.

\section{Methods}

\section{Study population}

The study was designed as a case-control study. Cases ( $n=188$ ) were recruited from the Department of Obstetrics and Gynaecology at Uppsala University Hospital, Karolinska University Hospital, Huddinge University Hospital and Danderyd University Hospital, Sweden. Eligible cases with a diagnosis of recurrent miscarriage, defined as three or more verified consecutive miscarriages in the first or second trimester of pregnancy (5-21 completed weeks of gestation), were identified in the out-patient registers of the participating clinics and invited to participate in the study. The women were included between April 292009 and June 302010. Women with known risk factors for recurrent miscarriage, such as systemic lupus erythematosus, diabetes mellitus type 1, severe thrombophilia and major chromosomal aberrations were not included in the study. Furthermore, two women with hyperthyroidism were excluded.

The control subjects $(n=391)$ were matched for age at first planned pregnancy and were randomly chosen from the Uppsala University Hospital biobank of pregnant women. Since May 31 2007, all women aged 18 and older attending the second trimester (16-19 weeks of gestation) routine ultrasound scan at Uppsala University Hospital have been approached for inclusion in this biobank, and inclusion to our study was ongoing until June 30 2010. In the control group, none had a history of miscarriage and $74.9 \%$ had at least two spontaneous pregnancies, including the ongoing pregnancy, resulting in a term ( $\geq 37$ weeks) birth of a live infant. Beyond that, the same inclusion and exclusion criteria were applied for the control group as for the cases.

Both cases and controls attended a brief health examination including measurements of weight and height and answered standardised questions on reproductive history. Further, we reviewed the medical records to obtain relevant information on pregnancy outcomes, health problems and medication.

According to routine clinical procedures, TSH-levels were analysed in all women when diagnosed with recurrent miscarriage. In the case-group, hypothyroidism was defined as TSH above the current defined upper limit of the reference range at the different hospitals. Pregnant controls at high risk for thyroid disease were subjected to selected TSH screening according to local guidelines based on international recommendations [6]. This casefinding procedure was applied in first or early second trimester of pregnancy, before routine ultrasound scan and inclusion in the study.

The study was approved by the Regional Ethics Committee of the Medical Faculty of Uppsala University Hospital and the Ethical Committee of the Karolinska Institutet, Stockholm. Informed consent was obtained from all women included in the study.

\section{Blood sample collection}

Blood samples were collected in EDTA-containing tubes and centrifuged at $1500 \mathrm{~g}$ for $10 \mathrm{~min}$. Plasma and buffy coat were separated and stored at $-20^{\circ} \mathrm{C}$.

\section{SNP-analysis}

Genomic DNA was extracted from blood using QIAamp ${ }^{\circledR}$ DNA Blood Maxi kits (Qiagen, Venlo, the Netherlands). The samples were genotyped for the SNP rs4704397 of PDE8B, using the TaqMan ${ }^{\circledR}$ SNP Genotyping Assay (Applied Biosystems, Foster City, CA, USA). Briefly, PCR reactions were performed in a 96 well plate in a total volume of $25 \mu \mathrm{l}$ for each reaction. Each reaction consisted of 1x TaqMan Universal PCR Master Mix (PCR buffer, ROX passive reference dye, dNTPs and AmpliTaq Gold polymerase), 1x SNP Genotyping Assay (sequence-specific forward and reverse primers to amplify the polymorphic sequence of interest, i.e. HRG exon 5 , TaqMan ${ }^{\circledR}$ MGB probes labelled with VIC ${ }^{\circledR}$ dye to detect allele 1 sequence and with $\mathrm{FAM}^{\mathrm{TM}}$ to detect allele 2 
sequence) and $10 \mathrm{ng}$ of genomic DNA. Cycling conditions were initiated for $10 \mathrm{~min}$ at $95^{\circ} \mathrm{C}$, followed by 40 cycles of $15 \mathrm{~s}$ at $92^{\circ} \mathrm{C}$ and 1 minute at $60^{\circ} \mathrm{C}$. Real time fluorescence detection was performed. The Sequence Detection System (SDS) Software (Applied Biosystems) was used to plot fluorescence $(\mathrm{Rn})$ values based on the signals from each well. The plotted fluorescence signals indicated which alleles were present in each sample.

\section{Statistics}

Demographic and clinical characteristics were compared between cases and controls or genotype groups using t-test and Chi-square tests. ANOVA was used for continous variables. Adjusted odds ratios (AOR) for recurrent miscarriage were calculated in multivariate regression analyses using the following variables: maternal age as completed years at the first pregnancy or first miscarriage, body mass index $\left(\mathrm{BMI}, \mathrm{kg} / \mathrm{m}^{2}\right)$ defined as BMI recorded at inclusion (cases) or BMI at first antenatal visit (controls), smoking during pregnancy (yes/no) defined as smoker during $\geq 1$ pregnancy ending with miscarriage (cases) or smoker at first visit to the prenatal centre in gestational week 10 (controls), and genotype (A/G as reference). Only variables with possible association with each outcome $(\mathrm{p}<0.25)$ in the bivariate analyses were entered into the final model. All significance tests were two-tailed. P-values $<0.05$ were considered as statistically significant. All statistical analyses were performed using SPSS 16.0 for Windows software pack (SPSS, Chicago, IL).

\section{Results}

Background characteristics and genotyping of PDE8B Demographic data and clinical characteristics for cases and controls are shown in Table 1. There were no differences between cases and controls concerning age $(\mathrm{p}=0.99)$. As expected, BMI was higher $(\mathrm{p}=0.033)$ and smoking (18.7\% vs. 10.7\%, p =0.015) and hypothyroidism ( $8.5 \%$ vs. $3.1 \%, p=0.006)$ were more common in women with recurrent miscarriage.

Table 1 Demographic data and clinical characteristics of the study population

\begin{tabular}{lccc}
\hline & Cases $(\mathbf{n}=\mathbf{1 8 8})$ & Controls $(\mathbf{n}=\mathbf{3 9 1})$ & $\mathbf{p}$-value \\
\hline Age, years & $30.1 \pm 5.8$ & $30.1 \pm 5.8$ & 0.989 \\
$\mathrm{BMI}, \mathrm{kg} / \mathrm{m}^{2}$ & $24.7 \pm 4.8$ & $23.9 \pm 4.0$ & 0.031 \\
Smokers, $\mathrm{n}(\%)$ & $34(18.1 \%)$ & $42(10.7 \%)$ & 0.015 \\
Hypothyroidism, $\mathrm{n}(\%)$ & $16(8.5 \%)$ & $12(3.1 \%)$ & 0.006 \\
\hline
\end{tabular}

Values are mean \pm standard deviation; $n$, numbers of women; BMI, body mass index: BMI at inclusion (cases), BMI at first antenatal visit (controls); Smokers: smoker during $\geq 1$ pregnancy ending with miscarriage (cases), smoker at first visit to the prenatal center in gestational week 10 (controls); Hypothyroidism: elevated serum TSH-levels according to local laboratory limits.
Table 2a Demographic data and clinical characteristics of the study population according to the SNP rs 4704397 genotype

\begin{tabular}{lccc}
\hline & $\begin{array}{c}\text { A/A } \\
(\mathbf{n = 1 1 0 )}\end{array}$ & $\begin{array}{c}\text { A/G } \\
(\mathbf{n}=\mathbf{2 6 6})\end{array}$ & $\begin{array}{c}\text { G/G } \\
(\mathbf{n}=\mathbf{2 0 3})\end{array}$ \\
\hline Age, years & $29.9 \pm 5.1$ & $30.5 \pm 6.0$ & $29.6 \pm 5.8$ \\
BMl at first antenatal visit, $\mathrm{kg} / \mathrm{m}^{2}$ & $23.6 \pm 4.2$ & $24.5 \pm 4.4$ & $24.1 \pm 4.3$ \\
Smokers, n (\%) & $16(14.5 \%)$ & $31(11.7 \%)$ & $29(14.3 \%)$ \\
\hline
\end{tabular}

Values are mean \pm standard deviation. No significant differences between the groups exist.

Among the 579 genotyped women, 110 (19.0\%) were homozygous carriers of A/A, 266 (45.9\%) were heterozygous carriers (A/G) and $203(35.1 \%)$ were homozygous carriers of G/G (Table 2a). Homozygous A/A and G/G carriers, compared to heterozygous carriers, were more common among women with recurrent miscarriage (Table 2b). Homozygous and heterozygous carriers were in accordance with the Hardy Weinberg equilibrium.

\section{Genotype and risk of recurrent miscarriage}

A bivariate analysis was performed including all known confounders. Based on the finding (Table 2b) that homozygous A/A and G/G carriers seemed to be more common in women with recurrent miscarriage, heterozygous A/G carriers were chosen as reference group in the logistic regression analyses. Bivariate associations between homozygous A/A as well as G/G carriers of SNP rs 4704397 in PDE8B and recurrent miscarriage were verified and a test for trend across all 3 genotypes was performed (Table 4). After adjustment for known confounders such as age, BMI and smoking, the association between homozygous A/A (AOR 1.63, 95\% CI 1.01 2.64, $\mathrm{p}=0.045$ ) and $\mathrm{G} / \mathrm{G}$ (AOR 1.52, 95\% CI 1.02 - 2.27, $\mathrm{p}=0.039)$ carriers of SNP rs 4704397 in PDE8B and recurrent miscarriage remained.

\section{Discussion}

PDE8B is known to be abundantly expressed in the thyroid and is of importance for thyroid function $[9,12,13,15]$. Increased levels of TSH have previously been shown in homozygous A/A carriers of SNP rs 4704397 in PDE8B and we hypothesized that there might be an association between A allele carriers and recurrent miscarriage. In our study, associations between

\section{Table 2b Distribution of SNP rs 4704397 genotype among controls and cases}

\begin{tabular}{lcccc}
\hline & Controls $(\mathbf{n}=391)$ & & \multicolumn{2}{c}{ Recurrent miscarriage (cases, $\mathbf{n = 1 8 8})$} \\
\cline { 5 - 6 } \cline { 5 - 5 } & & & All & Hypothyroidism \\
\hline A/A & $69(17.6 \%)$ & & $41(21.8 \%)$ & $3(18.8 \%)$ \\
A/G & $193(49.4 \%)$ & & $73(38.8 \%)$ & $4(25.0 \%)$ \\
G/G & $129(33.0 \%)$ & & $74(39.4 \%)$ & $9(56.2 \%)$ \\
\hline
\end{tabular}


homozygous A/A as well as homozygous G/G carriers of SNP rs 4704397 in PDE8B and recurrent miscarriage were found.

It has been shown that deranged levels of TSH in serum are related to inheritable factors in $65 \%$ of cases $[18,19]$. According to a genome-wide association scan in a Sardinian population, the specific SNP rs 4704397 in PDE8B has a strong association with increased levels of $\mathrm{TSH}$ and explains $2.3 \%$ of the variance in TSH. Each copy of the A allele was associated with an average increase of $0.13 \mu \mathrm{IU} / \mathrm{ml}$ in TSH serum concentrations [14].

Limitingly, as the study population was evaluated at clinics with different reference ranges for TSH analyses, and serum was not stored at time of diagnosis, TSH levels were unavailable for further analysis. Thus, we were not able to draw conclusions about whether the increased risk of recurrent miscarriage in homozygous A/A carriers in our material was mediated through relatively increased TSH levels. However, the prevalence of hypothyroidism was slightly, but not enough to be statistically significant, greater in homozygous A/A than in G allele carriers.

Based on the fact that homozygous A/A and G/G carriers, compared to heterozygous, were more common among women with recurrent miscarriage, we decided to use heterozygous carriers as references. This concept has been used before in other studies. When several different folate-metabolizing genes were analyzed, heterozygous rather than wild-type homozygous carriers, appeared to have higher pregnancy success rate after IVF treatment [20,21].

Not only A/A, but also homozygous carriers of the G/ G SNP rs 4704397 in PDE8B were more common among women with recurrent miscarriage. This finding is novel and the mediator of the association is unknown. The association is presumably not mediated by inadequate thyroid metabolism, since no association between homozygous G/G carriers and thyroid disease has been identified in previous studies. Consistent with this, the prevalence of hypothyroidism in G/G carriers did not differ from that of $\mathrm{A} / \mathrm{G}$ carriers in our study population (Table 2a). It is very likely that another mediator is underlying this association.

Moreover, it is noteworthy that G/G carriers were more common among hypothyroid women with recurrent miscarriage, compared to both controls and all cases (Table 2b). Thus, concerning recurrent miscarriage, it seems to be a disadvantageous combination to be G/G carrier and to suffer from hypothyroidism. However, it is important to remember that the number of women with hypothyroidism is quite small in this material.

The importance of PDE8B in the placenta and human ovaries is unknown, but the relevance of phoshodiesterases (PDE) in human reproduction has been discussed $[10,13]$. The mechanisms that regulate oocyte maturation in vivo and in vitro are still not well understood but the second messenger, cyclic adenosine mono-phosphate (cAMP), plays a critical role in maintaining the oocytes at meiotic arrest in the diplotene stage of the first meiotic prophase [22]. The PDEs inactivate and degrade cAMP in oocytes as a response to the ovulatory luteinizing hormone pulse and have thus been proposed as factors of importance for regulating oocyte maturation [23-25]. Furthermore, it has been shown that levels of cAMP in the oocyte at meiotic resumption correlate with oocyte competence and embryonic development [26,27]. Based on the knowledge that PDE activity is relevant for levels of cAMP in oocytes, the importance of SNP rs 4704397 in PDE8B for regulation of oocyte maturation would be one pathway of interest for further study.

Another limitation with our study is that cases and controls were screened for thyroid disease in different ways. According to routine clinical procedures, TSHlevels in all women with recurrent miscarriage were analyzed. Pregnant controls were subjected to selected TSH screening when considered to be at high risk for thyroid disease, in accordance with international guidelines [6]. Thus, the frequency of hypothyroidism might have been

Table 3 Factors associated with recurrent miscarriage

\begin{tabular}{|c|c|c|c|c|}
\hline & & $\begin{array}{c}\text { Unadjusted OR } \\
(95 \% \mathrm{Cl})\end{array}$ & $\begin{array}{l}\text { Adjusted OR } \\
\quad(95 \% \mathrm{Cl})\end{array}$ & $\begin{array}{c}\text { p-value } \\
\text { (Adjusted OR) }\end{array}$ \\
\hline$\overline{\text { Age }}$ & years & $1.0(0.97-1.03)$ & $0.99(0.96-1.02)$ & 0.500 \\
\hline $\mathrm{BMI}$ & $\mathrm{kg} / \mathrm{m}^{2}$ & $0.96(0.92-1.00)$ & $0.96(0.92-0.96)$ & 0.026 \\
\hline \multirow[t]{2}{*}{ Smoker } & No & 1 & 1 & \\
\hline & Yes & $1.84(1.12-3.00)$ & $1.86(1.12-3.09)$ & 0.017 \\
\hline \multirow[t]{3}{*}{ SNP rs4704397 } & $\mathrm{A} / \mathrm{G}^{*}$ & 1 & 1 & \\
\hline & $A / A$ & $1.57(0.98-2.52)$ & $1.63(1.01-2.64)$ & 0.045 \\
\hline & $\mathrm{G} / \mathrm{G}$ & $1.52(1.02-2.25)$ & $1.52(1.02-2.27)$ & 0.039 \\
\hline
\end{tabular}


underestimated in the control group, which is of importance when the results are evaluated.

Of course, we cannot exclude our results concerning SNP associations to be false positive. Generally, there is a high false positive rate in small genetic association studies due to low prior probability [28]. However, SNP rs 4704397 in PDE8B has been shown to be associated with variations in serum TSH levels in several studies [14-17], and there is a well known association between hypothyroidism and recurrent miscarriage [1]. To our knowledge, this is the first study examining a possible association between SNP rs 4704397 in PDE8B and recurrent miscarriage. To confirm our findings, it would be important to increase the sample size and replicate in an independent cohort in a further study.

\section{Conclusions}

Our findings suggest that there is an association between homozygous A/A as well as homozygous G/G carriers of SNP rs 4704397 in PDE8B and recurrent miscarriage.

In our study, different alleles of SNP rs 4704397 in PED8B were associated with the same outcome, recurrent miscarriage, but the explanation for this association is a subject for speculation. Genetic variability plays a role in many different diseases and has been proposed to be of relevance in screening for distinct syndromes with known genetic defects, and it might also be used for prediction of success related to disease treatment $[29,30]$.

Hypothetically, this specific SNP may be used for individual counselling and for optimising treatment to prevent recurrent miscarriage, based on which allele the woman is a carrier of.

However, larger studies with independent replication are needed to confirm our results and their clinical importance.

\section{Competing interests}

The authors declare no conflict of interest.

\section{Authors' contributions}

$\mathrm{HK}, \mathrm{FH}, \mathrm{LSS}, \mathrm{ASE}, \mathrm{KB} B \mathrm{BML}$ and ISP designed the study and were responsible for data collection. $H \AA$ designed the study, analyzed the data and drafted the manuscript. MG and AKW analyzed the data and drafted the manuscript. All authors read and approved the final manuscript.

\section{Acknowledgements}

The authors would like to thank all the women participating in the study and Christine Sund- Lundström, Department of Women's and Children's Health, Uppsala University for valuable technical assistance.

\section{Author details}

'Department of Women's and Children's Health, Uppsala University, Uppsala, Sweden. ${ }^{2}$ Department of Clinical Sciences, Division of Obstetrics and Gynaecology, Karolinska Institutet and Danderyd Hospital, Stockholm, Sweden. ${ }^{3}$ Department of Women's and Children's Health, Karolinska Institutet, Stockholm, Sweden. ${ }^{4}$ Department of Clinical Sciences, Intervention and Technology, Karolinska Institutet, Karolinska University Hospital Huddinge, Stockholm, Sweden.
Received: 19 April 2012 Accepted: 10 December 2012

Published: 13 December 2012

\section{References}

1. Ford HB, Schust DJ: Recurrent pregnancy loss: etiology, diagnosis, and therapy. Rev Obstet Gynecol 2009, 2(2):76-83.

2. Jauniaux E, Farquharson RG, Christiansen $O B$, Exalto N: Evidence-based guidelines for the investigation and medical treatment of recurrent miscarriage. Hum Reprod 2006, 21(9):2216-2222.

3. Sullivan AE, Silver RM, LaCoursiere DY, Porter TF, Branch DW: Recurrent fetal aneuploidy and recurrent miscarriage. Obstet Gynecol 2004, 104(4):784-788.

4. Stirrat GM: Recurrent miscarriage. Lancet 1990, 336(8716):673-675.

5. Rai R, Regan L: Recurrent miscarriage. Lancet 2006, 368(9535):601-611.

6. Abalovich M, Amino N, Barbour LA, Cobin RH, De Groot LJ, Glinoer D, Mandel SJ, Stagnaro-Green A: Management of thyroid dysfunction during pregnancy and postpartum: an Endocrine Society Clinical Practice Guideline. J Clin Endocrinol Metab 2007, 92(8 Suppl):S1-S47.

7. Casey BM, Leveno KJ: Thyroid disease in pregnancy. Obstet Gynecol 2006, 108(5):1283-1292.

8. Casey BM, Dashe JS, Spong CY, McIntire DD, Leveno KJ, Cunningham GF: Perinatal significance of isolated maternal hypothyroxinemia identified in the first half of pregnancy. Obstet Gynecol 2007, 109(5):1129-1135.

9. Hayashi M, Matsushima K, Ohashi H, Tsunoda H, Murase S, Kawarada Y, Tanaka T: Molecular cloning and characterization of human PDE8B, a novel thyroid-specific isozyme of 3',5'-cyclic nucleotide phosphodiesterase. Biochem Biophys Res Commun 1998, 250(3):751-756.

10. Hayashi M, Shimada Y, Nishimura Y, Hama T, Tanaka T: Genomic organization, chromosomal localization, and alternative splicing of the humanphosphodiesterase 8B gene. Biochem Biophys Res Commun 2002, 297(5):1253-1258.

11. Soderling SH, Bayuga SJ, Beavo JA: Cloning and characterization of acAMP- specific cyclic nucleotide phosphodiesterase. Proc Natl Acad Sci U S A 1998, 95(15):8991-8996.

12. Gamanuma M, Yuasa K, Sasaki T, Sakurai N, Kotera J, Omori K: Comparison of enzymatic characterization and gene organization of cyclic nucleotide phosphodiesterase 8 family in humans. Cell Signal 2003, 15(6):565-574.

13. Horvath A, Giatzakis C, Tsang K, Greene E, Osorio P, Boikos S, Libe R, Patronas Y, Robinson-White A, Remmers E, et al: A cAMP-specific phosphodiesterase (PDE8B) that is mutated in adrenal hyperplasia is expressed widely in human and mouse tissues: a novel PDE8B isoform in human adrenal cortex. Eur J Hum Genet 2008, 16(10):1245-1253.

14. Arnaud-Lopez L, Usala G, Ceresini G, Mitchell BD, Pilia MG, Piras MG, Sestu N, Maschio A, Busonero F, Albai G, et al: Phosphodiesterase 8B gene variants are associated with serum TSH levels and thyroid function. Am J Hum Genet 2008, 82(6):1270-1280.

15. Horvath A, Faucz F, Finkielstain GP, Nikita ME, Rothenbuhler A, Almeida M, Mericq $V$, Stratakis CA: Haplotype analysis of the promoter region of phosphodiesterase type 8B (PDE8B) in correlation with inactivating PDE8B mutation and the serum thyroid-stimulating hormone levels. Thyroid 2010, 20(4):363-367.

16. Taylor P, Panicker V, Sayers A, Shields B, lqbal A, Bremner A, Beilby J, Leedman P, Hattersley A, Vaidya B, et al: A meta-analysis of the associations between common variation in the PDE8B gene and thyroid hormone parameters; including assessment of longitudinal stability of associations over time and effect of thyroid hormone replacement. Eur J Endocrinol 2011, 10:0938. EJE.

17. Shields BM, Freathy RM, Knight BA, Hill A, Weedon MN, Frayling TM, Hattersley AT, Vaidya B: Phosphodiesterase 8B Gene Polymorphism Is Associated with Subclinical Hypothyroidism in Pregnancy. J Clin Endocrinol Metab 2009, 94(11):4608-4612.

18. Hansen PS, Brix TH, Sorensen TI, Kyvik KO, Hegedus L: Major genetic influence on the regulation of the pituitary-thyroid axis: a study of healthy Danish twins. J Clin Endocrinol Metab 2004, 89(3):1181-1187.

19. Panicker V, Wilson SG, Spector TD, Brown SJ, Falchi M, Richards JB, Surdulescu GL, Lim EM, Fletcher SJ, Walsh JP: Heritability of serum TSH, free T4 and free T3 concentrations: a study of a large UK twin cohort. Clin Endocrinol (Oxf) 2008, 68(4):652-659.

20. Laanpere M, Altmae S, Stavreus-Evers A, Nilsson TK, Yngve A, Salumets A: Folate-mediated one-carbon metabolism and its effect on female fertility and pregnancy viability. Nutr Rev 2010, 68(2):99-113. 
21. Laanpere M, Altmae S, Kaart T, Stavreus-Evers A, Nilsson TK, Salumets A: Folate-metabolizing gene variants and pregnancy outcome of IVF. Reprod Biomed Online 2011, 22(6):603-614.

22. Shu YM, Zeng HT, Ren Z, Zhuang GL, Liang XY, Shen HW, Yao SZ, Ke PQ, Wang NN: Effects of cilostamide and forskolin on the meiotic resumption and embryonic development of immature human oocytes. Hum Reprod 2008, 23(3):504-513.

23. Conti M, Andersen CB, Richard F, Mehats C, Chun SY, Horner K, Jin C, Tsafriri A: Role of cyclic nucleotide signaling in oocyte maturation. Mol Cell Endocrinol 2002, 187(1-2):153-159.

24. Sasseville M, Albuz FK, Côté N, Guillemette C, Gilchrist RB, Richard FJ: Characterization of Novel Phosphodiesterases in the Bovine Ovarian Follicle. Biol Reprod 2009, 81(2):415-425.

25. Sela-Abramovich S, Edry I, Galiani D, Nevo N, Dekel N: Disruption of gap junctional communication within the ovarian follicle induces oocyte maturation. Endocrinology 2006, 147(5):2280-2286.

26. Luciano AM, Pocar P, Milanesi E, Modina S, Rieger D, Lauria A, Gandolfi F: Effect of different levels of intracellular CAMP on the in vitro maturation of cattle oocytes and their subsequent development following in vitro fertilization. Mol Reprod Dev 1999, 54(1):86-91.

27. Luciano AM, Modina S, Vassena R, Milanesi E, Lauria A, Gandolfi F: Role of intracellular cyclic adenosine 3',5'-monophosphate concentration and oocyte- cumulus cells communications on the acquisition of the developmental competence during in vitro maturation of bovine oocyte. Biol Reprod 2004, 70(2):465-472.

28. Wacholder S, Chanock S, Garcia-Closas M, El Ghormli L, Rothman N: Assessing the probability that a positive report is false: an approach for molecular epidemiology studies. J Natl Cancer Inst 2004, 96(6):434-442.

29. Fridley BL, Biernacka JM: Gene set analysis of SNP data: benefits, challenges, and future directions. Eur J Hum Genet 2011, 19(8):837-843.

30. Chan IS, Ginsburg GS: Personalized medicine: progress and promise. Annu Rev Genomics Hum Genet 2011, 12:217-244.

doi:10.1186/1471-2350-13-121

Cite this article as: Granfors et al:: Phosphodiesterase 8B gene polymorphism in women with recurrent miscarriage: A retrospective case control study. BMC Medical Genetics 2012 13:121

\section{Submit your next manuscript to BioMed Central and take full advantage of:}

- Convenient online submission

- Thorough peer review

- No space constraints or color figure charges

- Immediate publication on acceptance

- Inclusion in PubMed, CAS, Scopus and Google Scholar

- Research which is freely available for redistribution 